\title{
A medical perspective on the adventures of Sherlock Holmes
}

James Reed Russells Hall Hospital Dudley

\begin{abstract}
The adventures of Sherlock Holmes, although primarily famous as stories of detection of crime, offer a considerable amount to interest the medical reader. There are many medical references in the stories, and the influence of Conan Doyle's medical background is clearly seen in the main characters. Aspects of the stories also reflect Conan Doyle's medical career, and also something of his attitude towards the profession. From Holmes's sayings and accounts of his methods, parallels can be drawn between Holmesian deduction and the diagnostic process. It is concluded, however, that deduction cannot be used as a direct paradigm since medical problems are rarely soluble through a process of logic alone.

(F Med Ethics: Medical Humanities 2001;27:76-81)
\end{abstract}

Keywords: Sherlock Holmes; literature; diagnosis

\section{Introduction}

The adventures of Sherlock Holmes, as written by Sir Arthur Conan Doyle between the years of 1887 and 1929, are well known and well respected the world over. Although primarily famous as stories of detection of crime, there is a considerable amount to interest the medical reader-not least the parallels between the Holmesian methods of logical reasoning and deduction and the diagnostic process employed by doctors. Moreover, the stories owe a great deal in their construction and execution to medicine-a prime example being constituted by the person and actions of one of the main protagonists, Dr John Watson.

The extent of the medical dimension has been crudely quantified by Key and Rodin thus:

"Included within the 60 Holmes adventures are references to 68 diseases, 32 medical terms, 38 doctors, 22 drugs, 12 medical specialties, 6 hospitals and even 3 medical journals and 2 medical schools. Conan Doyle often patterned characters in his writings after medical school professors and friends. Also on record are 42 of his real patients with the nature of the illness available for 31 of them. Many of the real patients have their fictional counterparts in the Holmes adventures."

This paper aims to explore the issues raised above in some detail, to consider various other interesting medical references in the canon and finally to consider the relationship between Holmesian deduction and modern medicine. The most appropriate starting point is a consideration of important personalities associated with the stories, both fictional and non-fictional.

\section{Important personalities}

SIR ARTHUR CONAN DOYLE

Much can be gained in a discussion of these works by a consideration of the life of the author, Sir Arthur Conan Doyle. Such is the popularity of his creation that in the minds of many, Holmes has achieved the status of an historical rather than a fictional character. In the process, the author himself is often overlooked.

Conan Doyle was born in 1859. After schooling, he entered medical school at the University of Edinburgh, from which he graduated in 1881 at the age of 22 . He worked as a ship's doctor for a time, visiting first the Arctic and then the west coast of Africa. Returning to England, he served as an assistant to a medical school colleague (George Budd), but this proved to be unsatisfactory and Conan Doyle opened his own practice in Southsea in 1882. It was during this period that he wrote the first two Sherlock Holmes adventures: A Study in Scarlet and The Sign of Four. ${ }^{2}{ }^{3}$ His practice flourished, but in 1890 he felt in need of a change of direction and studied in Vienna to become an oculist. He returned to England shortly afterwards and opened an office in London. Patients were, however, few and far between and this left him with plenty of time to write. The first of the 56 short stories involving Holmes was published in The Strand magazine of July $1891 .{ }^{4}$

\section{MR SHERLOCK HOLMES}

The great detective himself is the central character in the stories. Although he apparently holds no medical qualifications, references in A Study in Scarlet show that he has a healthy interest in such matters. ${ }^{2}$ Indeed, he is first encountered by Watson in a London hospital laboratory, devising a test for haemoglobin.

In developing the character of Sherlock Holmes, Conan Doyle drew heavily on his medical experience. One particular influence was $\mathrm{Dr}$ Joseph Bell-a distinguished doctor who worked at Edinburgh Royal Infirmary. In Conan Doyle's own words:

"The most notable of the characters whom I met was one Joseph Bell, surgeon at the Edinburgh Infirmary... . He was a very skilful surgeon, but his strong point was diagnosis, not only of disease, but 
of occupation and character... . [As his outpatient clerk] I had ample chance of studying his methods and of noticing that he often learned more of the patient by a few quick glances than I had done by my questions." 5

Conan Doyle recounts several examples of one of Bell's deductions, which bear striking similarities to Holmes's deductions in the adventures. Bell is an undoubted influence upon the character of Holmes (Conan Doyle was later to write to Bell saying: "My dear Doctor Bell, it is most certainly to you that I owe Sherlock Holmes", ${ }^{6}$ ) but it would be wrong to say that Holmes is a direct fictional representation of him-the characters differ in many ways, not least in their chosen professions. Moreover, Conan Doyle wrote that although Bell "took a keen interest" in Holmes and went so far as to suggest ideas for further adventures, these ideas "were not ... very practical".

DR JOHN H WATSON

Perhaps the most immediately obvious medical reference in the canon is personified in Dr WatsonHolmes's companion and chronicler of all but four of the adventures.

The first point to make concerns Watson's intelligence. It is commonly assumed that Watson is somewhat slow-witted. This myth probably has its origins in the films of the 1930s and 1940s starring Basil Rathbone as Holmes and Nigel Bruce as Watson. Although endearing in the context of the film, Bruce's portrayal of Watson as a bumbling buffoon has led to the general assumption that this is how Watson acts in the books. In fact, Watson is a man of education, graduating with an MD from the University of London in 1878. He then undertook further training with a view to being commissioned as an army surgeon. On completing this training he caught up with his regiment in India, which had become embroiled in the second Afghan war. After being shot (with some doubt as to the site) by a Jezail bullet, he was admitted to a field hospital where he contracted "enteric fever" (a strange coincidence: Conan Doyle was later to work in just such a hospital). After a long period struggling for his life, he was sent straight back to England to recover, and seek some civilian employment.

Watson has therefore had a far from humdrum background, and this lends him physical and mental toughness, which is often brought to the fore in the adventures. Few other professional "intelligentsia" (for instance lawyers) could have believably had such experiences, and they add considerably to Watson as a character. Many times over the course of the stories his experiences in India come into play. Also, whenever there is danger at hand it is Watson who carries his trusty army revolver-and presses it into service on more than one occasion (as when attacking the hound in The Hound of the Baskervilles).

Returning to this issue of Watson's intelligence, there is considerable evidence in the canon and in some other related works that Watson strove to emulate Holmes's skills-with (as he says himself) "indifferent" success-but very often the deductions he produces are plausible and intelligent, even though the end result is incorrect. An example of this is the little-known "How Watson learned the trick", a short dialogue published in The Book Of The Queen's Doll's House Library in 1924. An extract is reproduced below:

" I I am able to say that you were greatly preoccupied when you got up this morning.' [said Watson] 'Excellent!' said Holmes. 'How could you possibly know that?' 'Because you are usually a very tidy man and yet you have forgotten to shave.'

'Dear me! How very clever!' said Holmes. 'I had no idea, Watson, that you were so apt a pupil. Has your eagle eye detected anything more?' 'Yes, Holmes. You have a client named Barlow, and you have not been successful in his case.'

'Dear me, how could you know that?'

'I saw the name outside his envelope. When you opened it you gave a groan and thrust it into your pocket with a frown on your face.'..

'Just a little [mistaken], I fear [said Holmes]. Let us take the points in their order: I did not shave because I have sent my razor to be sharpened. I put on my coat because I have, worst luck, an early meeting with my dentist. His name is Barlow, and the letter was to confirm the appointment... . But go on, Watson, go on! It's a very superficial trick, and no doubt you will soon acquire it.","

\section{Watson's medical rôle}

An oft-quoted, albeit shallow explanation for Watson's portrayal as a doctor is simply that Conan Doyle chose the profession of which he had the most personal experience, and which was closest to his heart. This is no doubt a contributory, but not primary factor. Indeed, it might be argued that Watson's medical role is purely incidental, serves no real purpose in the adventures, and that the character of Watson would have functioned equally well as a lawyer, professor or similarly educated person. On cursory examination, this seems reasonableWatson's medical nature is never really asserted, and he spends most of his time as an intellectual foil for Holmes. On further consideration, however, it becomes clear that Watson's medical persona is indicative of deeper issues.

It seems possible that (perhaps without realising it) Conan Doyle was illustrating through his characters two sides to his own personality in a "Jekyll and Hyde" manner. Holmes represents one side of the coin-of exceptional ability, seized with bouts of intense activity and then relapsing into periods of extreme listlessness and lethargy. Watson on the other hand is solid, reliable and capable-yet unable to match to any degree the bursts of frantic activity exhibited by his opposite number, nor yet the ability to solve problems. With reference to Conan Doyle's life, both these traits can be seen in his personality. His time in Southsea represents Watson; his sudden passion for ophthalmology and dash to Vienna represents Holmes. 
It could be argued that there is an unspoken criticism of medical practice inherent in the adventures, accentuated by making Watson a representative of the medical profession. One could imagine Conan Doyle through the mouthpiece of Holmes scoffing at (as he sees it) the plodding, formulaic methods employed by some of his colleagues as compared with those used by the likes of Joseph Bell.

This criticism revolves around the use of imagination. At numerous times in the stories, Holmes is heard to extol the value of imaginationand to deplore its lack in his colleagues at Scotland Yard. For example, consider this extract from The Adventure of the Norwood Builder, in The Return of Sherlock Holmes.

"'It strikes me, my good Lestrade, as being just a trifle too obvious,' said Holmes. 'You do not add imagination to your other great qualities'..."10

Similarly in this extract from Silver Blaze in The Memoirs of Sherlock Holmes:

"'See the value of imagination,' said Holmes. 'It is the one quality which Gregory lacks. We imagined what might have happened, acted upon the supposition, and find ourselves justified..." "11

In Holmes's constant pleas for imagination, one can almost perceive early stirrings of holistic medicine. One of the reasons for Holmes's success is that he looks to the wider picture-he does not restrict himself to the bare facts, but uses his imagination and knowledge to formulate theories beyond what is immediately apparent. The holistic approach to medicine encourages such strategies.

MYCROFT HOLMES

There is one final aspect to consider in terms of symbolic representations, and that is the character of Mycroft Holmes, brother to Sherlock. He first appears in The Greek Interpreter in The Memoirs of Sherlock Holmes and is described initially by Holmes as being "...My superior in observation and deduction...”"

On being questioned by Watson regarding why he has not come to the notice of public or police, Holmes goes on to say:

“....he has no ambition and no energy. He will not even go out of his way to verify his own solutions, and would rather be considered wrong than take the trouble to prove himself right.",12

The character of Mycroft can be regarded as a sideswipe at the more indolent members of the medical profession. Conan Doyle, with his drive and enthusiasm must have found lack of "ambition and energy" in his colleagues very difficult to understand, and indeed to forgive.

\section{Detection and the diagnostic process}

Diagnostic medicine may be likened to detective work, in so far as processes of observation and deduction are employed in order to arrive at a con- clusion. The methods of Sherlock Holmes have frequently been used ${ }^{13}$ as a paradigm for the diagnostic process, due in no small part to the medical background outlined above. There are a number of parallels between detection and diagnosis which should be considered.

The normal diagnostic process undertaken by a modern physician encompasses three separate components: history, physical examination and investigations, each contributing less than the preceding one. This process is mirrored closely by that of Sherlock Holmes (especially in the short stories) and is characterised by a methodical and logical approach. Holmes is also a great advocate of observation, in which the trained eye picks up signs (otherwise missed) which have an important bearing on the solution to the problem. His skill rests primarily on his ability to observe minutiae and use them to arrive at a conclusion. This is a skill still taught to modern medical undergraduates as being of great importance.

In arriving at his conclusions, Holmes relies chiefly on his methodical approach-on only very rare occasions does luck play a part. His detective process consists of a detailed interview with the client (the history), followed by a similarly detailed examination of the scene of the events (where applicable) and concluded by a series of other investigations (such as telegrams, interviews with others, etc). The solution to the problem is presented (usually with the arrest of the criminal) to the onlookers in the manner of medical case presentation, and is followed by discussion and questions.

This methodical process is not seen nearly so clearly in other famous fictional detectives. For example, those portrayed by Agatha Christie generally make observations as they go along, without any obvious method (and indeed, often depending on lucky chance). Although one can admire the acumen of Hercule Poirot or Miss Marple, comparatively little insight is given into the processes of detection they employ.

It is interesting to note that Holmes himself criticises other literary detectives of the time, who might be said to have similar methods. In $A$ Study in Scarlet he is heard to be very disparaging of Edgar Allan Poe's "Dupin" and of Gaboriau's "Lecoq", describing the former as "... a very inferior fellow ..." and the latter as "... . a miserable bungler...". ${ }^{14}$

\section{Important textual references}

At many times throughout the adventures, Holmes makes comments about how he arrives at his conclusions. These comments epitomise his methods, and also can be used to demonstrate clearly how closely aspects of Holmesian detection compare with the diagnostic process.

A selection of these comments is considered here. In A Study in Scarlet: "It is a capital mistake to theorise before you have all the evidence." 15

The link to medical practice is clear-in particular, the folly of making assumptions or guesses before the facts of the matter are ascertained as best 
as possible. In The Adventure of Black Peter, from The Return of Sherlock Holmes:

"One should always look for a possible alternative, and provide against it. It is the first rule of ... investigation. ... you should never lose sight of the alternative." 16

Again, these precepts are very important in the medical world. A very common mistake is to develop a preconception about what a particular diagnosis is, and attempt to make the various facts of the case fit with that preconception ("the crime of Procrustes"). The results cannot be good for the patient-leading to delay of correct treatment at best, or to incorrect and potentially harmful treatment at worst.

In The Reigate Puzzle from The Memoirs of Sherlock Holmes:

"It is of the highest importance in the art of detection to be able to recognise, out of a number of facts, which are incidental and which vital. Otherwise your energy and attention must be dissipated instead of being concentrated." ${ }^{\prime 7}$

This is as true for medicine now as in the closing years of the 19th century. During his investigations, the doctor is bombarded on all sides by information, much of which is irrelevant to the problem under consideration. This is even more the case today, with the wide range of chemical tests, imaging and other investigations that are available. Having the ability to sift from all this data only what is important is of great value in diagnosis. In The Boscombe Valley Mystery in The Adventures of Sherlock Holmes: "[My method] is founded upon the observation of trifles." 18

Again, the importance of observing the fine details is stressed; such "trifles" taken together can be central to arriving at a diagnosis. For example, a bluish tint to the whites of the eyes may suggest a diagnosis of osteogenesis imperfecta. Also pitted fingernails in psoriatic arthritis are easily missed, but can be crucial in making the diagnosis.

Finally, in The Sign of Four, perhaps Holmes's most celebrated comment: "When you have eliminated the impossible, whatever remains, however improbable, must be the truth.”19

The simple truth of this is self-evident. Often in the process of differential diagnosis, the answer is arrived at by a process of elimination-and it is important not to discount the result even if initially it seems unlikely.

\section{Other medical references}

Other less immediately obvious aspects of medical practice are found in the stories. For example, Holmes could be said to be an expert history-taker. Medical students are taught to use open questions, allow the patient to talk as much as possible and only then ask precisely targeted questions to narrow down the range of possible diagnoses. Furthermore, the history should provide enough information to allow the formulation of a reasonable working diagnosis (or hypothesis).
In Holmes's consultation with his clients, he employs all of the above devices. A good example of this is contained in the short story, The Yellow Face, taken from The Memoirs of Sherlock Holmes. The bulk of the passage (being a description of the case) is omitted; only Holmes's actual questions are quoted:

Examples of the open questions:

"Might I beg you, as time may prove to be of importance, to furnish me with the facts of your case without further delay?..."

“... Kindly let me have the facts, Mr Munro ..."

Examples of the closed, directed questions:

“... Tell me ... could you swear that this was a man's face at the window?"

“... How long is it since your wife asked you for a hundred pounds?" 20

The switch from open questions (eliciting the salient points of the client's story) to directed closed questions (clearing up individual details) is marked. Moreover Holmes has apparently formulated a theory while listening to the story, and then asks these questions in order to test it. This compares closely with the "ideal" method of taking a historybearing in mind all the possible diagnoses, and then asking appropriate questions to rule them in or out.

Having no other information (and without any further investigation), Holmes is now able to construct a "diagnosis": "[Watson speaking] "You have a theory?'

'Yes, a provisional one. But I shall be surprised if it does not turn out to be correct. This woman's first husband is in that cottage." "21

In the event, this does in fact prove to be incorrectdemonstrating that even the most skilled of their profession are not infallible. This passage serves, however, as a good illustration of Holmes's methods.

\section{Holmesian deduction and modern medicine}

Thus far, parallels have been drawn between the diagnostic process and the detective methods of Sherlock Holmes. It is now appropriate to consider some problems (originally raised by Oderwald and Sebus ${ }^{22}$ ) with drawing such parallels.

A commonly used metaphor for criminal detection is that of a jigsaw puzzle. The story begins with a problem (such as a murder), and is then quickly followed by a mass of facts. The detective then pieces together the available facts, asking the appropriate questions and finally is able to complete the puzzle, denouncing the criminal.

Peschel and Peschel contend that the same metaphor can be applied to the diagnostic process: "Diagnosing an illness is often like trying to put together a complicated jigsaw puzzle with the hitch that you cannot have all the pieces." ${ }^{13}$ This argument, however, presents a number of problems. The reason why the jigsaw metaphor works 
for the detective story has much to do with the way in which such stories are written. The guiding principle of a jigsaw puzzle is that there is a final picture-the one cannot exist without the other, and likewise the existence of the one is instrumental in the manufacture (and very often the solving) of the other. The author of the detective story is able to construct his story in much the same way-that is backwards from the solution of the mystery. Since there is a final "picture", generating a series of events which logically leads up to that picture is a manageable task. If done skilfully, the result is that an apparently meaningless morass of facts at the beginning miraculously comes together at the end to form a coherent whole. Unfortunately, clinical situations rarely have such a well-defined picture at the end-not only (as Peschel and Peschel say) do we not have all the pieces, we may have pieces that do not fit very well or are from an entirely different puzzle altogether. ${ }^{13}$

Oderwald and Sebus suggest ${ }^{22}$ three main characteristics of a Holmes story which can be extracted from the jigsaw metaphor:

1. Holmes moves very smoothly from the initial problem through to the solution. Seldom does he follow rabbit trails, or spend a long time casting around for ideas. This is a function of the story being written from back-to-front.

2. Since the picture is made complete at the end, it is possible to look back over the story and decided whether all the various facts, implications and hypotheses were correct or not.

3. Coincidences and chance have little role to play in the stories. It is always down to Holmes's genius rather than blind luck that facts are recognised as being of importance.

These characteristics can be used to illustrate the difference between fictional accounts and real life, in which none of the above apply. Cold discussion of the diagnostic process in abstract and in case histories fulfils the criteria for fictional accounts, rather than real life. Case histories are also written from end to beginning, the eventual diagnosis representing the "picture". In doing this, it is possible to describe the various facts surrounding the case in such a way that all are accounted for, and the result will form a logical whole. This is very often far from the actual process itself, but merely a synthesis of the processes leading to the eventual result. With hindsight, it is possible to identify and extract only those processes which are important in producing the result and hence the case history as written is artificial.

Oderwald and Sebus cite a typical example of a case history which falls into this trap. It is one of a series described by Peschel and Peschel ${ }^{13}$ which purports to demonstrate Holmesian deduction. It concerns a man admitted with a mysterious liver necrosis. None of the usual risk factors are present, and although the patient recovers uneventfully the doctors are frustrated at not knowing what was responsible. Finally, a chance remark of the patient's that he works in a dry cleaners and inhaled some fumes a few days before being taken ill give the doctors the clue they need to pronounce that tetrachloromethane was the cause of the trouble.

The first thing to say is that this story does not illustrate a diagnostic process as such. Although the "case" would not be solved without knowing the cause, the treatment of the patient would not necessarily be altered, and in the event the patient recovered perfectly well without this knowledge. Secondly, the vital "clue" was delivered purely by coincidence, not relying to any degree on the acumen of the treating doctors, nor indeed to any process of logic. The final step between knowing about inhaling dry-cleaning chemicals and liver disease is a simple one, requiring only recourse to appropriate textbooks. The case is written up, however, in an outcome-oriented manner, whereby the final result (discovery of poisoning by tetrachloromethane) is seen to be the logical conclusion of the diagnostic process as a whole. This is not so-any logical progression seen is merely as a result of the retelling, rather than of the actual events. Peschel and Peschel have reduced the relatively complex sequence of real events to a single, simple line of logic (which in any case does not cogently hold together).

The conclusion from this is that comparing Holmesian deduction to the process of diagnosis is an oversimplification. Very rarely does diagnosis of disease consist of a simple trail of logic from problem to solution. The facts of the presenting complaint are clearly important, but at a more abstract level elements of the experience of the doctor (the "gut feeling") come into play. One could imagine Holmes being very dismissive of such "fancies".

Added to this is the problem that real life is seldom so obliging as to provide unique sets of "clues" for the solution of each "problem". Medicine contains few absolutes-the clinical pictures painted by the textbooks are seldom seen in their entirety in real life. The same set of clues could suggest different diagnoses to different people, and likewise the same diagnosis can be reached by a variety of different routes. In either case, the route to the diagnosis could appear logical, but still be incorrect. A Holmesian problem is proved or disproved by the train of logic alone.

Finally, there are cases in which there is no "solution" in the manner discussed above. Owing to our very limited understanding of the workings of the brain, modern medicine is equally limited in its understanding of brain disorders (being both neurological and psychiatric). Such cases can present in a wide variety of forms, and make the description of a logical sequence from symptoms and signs to final diagnosis much more difficult.

Deductive reasoning as employed by Sherlock Holmes undoubtedly forms an important part of the modern medical diagnostic process. The real skill of the doctor lies, however, in operating simultaneously on a variety of levels, pulling together straightforward factual knowledge with more abstract impressions and experiences to produce an appropriate response. This response may not 
necessarily lead to the solving of the "mystery" (the cause of the patient's illness), but it should lead to the solving of the "problem"(helping a sick patient). The problem may not necessarily be resolved as a direct result of the medical interventions, but simply as result of an effort being made (for example, supportive care following GuillainBarré syndrome paralysis).

A parallel can be found in the Holmes stories. In The Yellow Face (from The Memoirs of Sherlock Holmes, ${ }^{23}$ as mentioned above) Holmes develops a totally erroneous theory, but in the pursuit of it uncovers the truth-not as a result of his knowledge or any deductive process, but instead as a result of his presence and his energy being directed at the problem. This is a situation in which doctors frequently find themselves.

The validity of analysing Sherlock Holmes Discussion of Sherlock Holmes would not be complete without a consideration of the author's attitude towards the adventures. Conan Doyle is known to have been dismissive of them, regarding them more as a way of earning money than achieving great literature. Indeed, he describes them in the introduction to The Casebook of Sherlock Holmes as being part of "the fairy kingdom of romance". It could be argued that this would render the analysis of Holmes's methods invalid, since Conan Doyle was merely setting out to write a good story rather than seriously describing scientific investigations. Whatever his opinions concerning the stories may have been, however, his own knowledge and experience would undoubtedly come through in anything he wrote. Analyses are therefore of value to bring out both intentional and perhaps unintentional references and parallels between Conan Doyle's "fairy kingdom" and our real world.

\section{Conclusion}

In conclusion therefore, the medical background of their author shows clearly through the Sherlock Holmes adventures. There are many medical overtones and allusions, not to mention direct references. Furthermore, at a more abstract level the characters in the stories can be thought of as representing aspects of medical practice at the time the stories were written. Further to this, many similarities can be drawn between the deductive methods of Holmes and the diagnostic process of modern doctors.
As has been discussed at length, however, these similarities refer to only one level of what is in reality a multilayered process. It has been said that Sherlock Holmes would have made a superb diagnostic physician, but is this really the case? It seems more likely that he would have been severely frustrated by the lack of logic in medicine, and by the number of occasions on which his carefully reasoned conclusions would be either proved incorrect by mere chance, or never proved at all. Medicine would offer little to keep him from returning to the familiar world of chemical bottles, magnifying glasses and fine tobacco.

Fames Reed was a medical student at the University of Birmingham at the time of writing. He is now working as a House Officer at Russells Hall Hospital in Dudley.

\section{References and notes}

1 Key JD, Rodin AE. Medical reputation and literary creation: an essay on Arthur Conan Doyle versus Sherlock Holmes essay on Arthur Conan Doyle versus Sherlock

2 Conan Doyle A. A study in scarlet. The complete Sherlock Holmes. London: Magpie Books Ltd, 1993. Unless otherwise stated all references to the works of Sir Arthur Conan Doyle are to be found in the compendium, The complete Sherlock Holmes.

3 Conan Doyle A. The sign of four.

4 Conan Doyle A. A scandal in Bohemia. The Strand 1891 July.

5 Conan Doyle A. Memories and adventures. London: Hodder \& Stoughton; 1924: 25-6.

6 Baring-Gould WS, ed. The annotated Sherlock Holmes. The four novels and fifty-six short stories completed by Sir Arthur Conan Doyle [2nd ed]. New York, NY: Clarkson N Potter Inc, 1967.

7 Conan Doyle A. The hound of the Baskervilles: 757.

8 Conan Doyle A. The return of Sherlock Holmes: 483.

9 Conan Doyle A. How Watson learned the trick. In: Lucas EV, Conan Doyle A. How Watson learned the trick. In: Lucas EV,
ed the queen's doll's house library. London: Methuen, 1924.

10 Conan Doyle A. The return of Sherlock Holms: 501.

11 Conan Doyle A. The memoirs of Sherlock Holmes: 344

12 Conan Doyle A. The memoirs of Sherlock Holmes: 436.

13 Peschel RE, Peschel E. What physicians have in common with Sherlock Holmes: discussion paper. Fournal of the Royal Society of Medicine 1989;82:33-6.

14 Conan Doyle A. A study in scarlet: $24-5$.

15 Conan Doyle A. A study in scarlet: 27.

16 Conan Doyle A. The return of Sherlock Holmes: 567.

17 Conan Doyle A. The memoirs of Sherlock Holmes: 407.

18 Conan Doyle A. The adventures of Sherlock Holmes: 214.

19 Conan Doyle A. The sign of four: 111.

20 Conan Doyle A. The sign of four. 11.

20 Conan Doyle A. The memoirs of Sherlock Holmes: $353-8$

22 Oderwald AK, Sebus JH. The physician and Sherlock

Oderwald AK, Sebus JH. The physician and Sherlock Holmes. fournal of the Royal Society of Medicine 1991;84:151-2.

23 Conan Doyle A. The memoirs of Sherlock Holmes: 350-62. 24 Conan Doyle A. The casebook of Sherlock Holmes: I. Also consulted:

Westmoreland BF, Key JD. Arthur Conan Doyle, Joseph Bell and Sherlock Holmes. Archives of Neurology 1991;48:325-9. 